\title{
OBITUARY
}

\section{Donald (Don) Leonard Fisher-Jeffes}

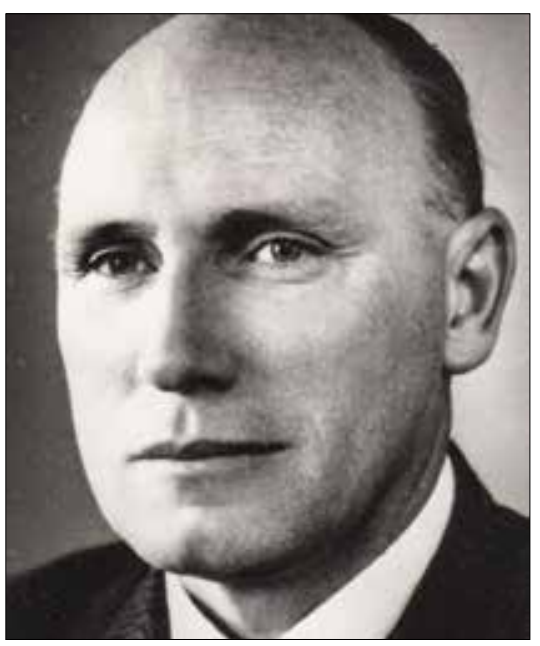

Dr Donald (Don) Fisher-Jeffes passed away in Cape Town on 5 September 2017 at the age of 98. Born in Sydney, Australia, on 3 June 1919, he emigrated to South Africa with his family in 1930, when his father Norman opened South Africa's first WeetBix factory in Cape Town. Don matriculated at Wynberg Boys' High School and studied medicine at the University of Cape Town, graduating MB ChB in 1944.

Don's interest in anaesthesia developed while he was an intern at Nokuphila Mission Hospital on the Witwatersrand. He then transferred to the newly opened Coronation Hospital, where after obtaining the Diploma in Public Health in 1946, he continued his training in anaesthesia under the tutelage of Dr Molly Barlow. In 1949 Don was one of the first group of three graduates to pass the University of the Witwatersrand's Diploma in Anaesthesia, South Africa's first specialist anaesthetic examination. He continued his association with the Johannesburg group of teaching hospitals, initially as a full-time specialist and after 1955 as a part-timer at Coronation Hospital. For 14 years he was in practice with Dr Cyril Frost.

Don developed a special interest in the fledgling subspecialty of cardiothoracic anaesthesia and was involved in many of the early repairs of congenital tracheo-oesophageal fistulas performed in Johannesburg. He provided anaesthesia for the pioneering cardiac catheterisation procedures performed by Drs Morris McGregor and Bernard van Lingen at Johannesburg Hospital in the 1950s.

A long-time servant of the South African Society of Anaesthesiologists (SASA), Don was a member of the SASA Council for 43 years. During this time he served two terms as secretary and two terms as president. During his second term as president he developed unstable angina and underwent successful coronary artery bypass surgery. In 1970 he was awarded SASA's highest honour, that of honorary life vice-president.

Don is survived by his second wife Suzanne and his three children from his marriage to his first wife, Doreen, who passed away in 1982. His son Norman is a neurosurgeon in Cape Town.

\section{Peter Gordon}

Archivist, South African Society of Anaesthesiologists Cape Town, South Africa

peter.gordon@uct.ac.za 